\title{
Endocrine diseases as causes of secondary hyperlipidaemia
}

\author{
Łukasz Bułdak1, Bogdan Marek², Dariusz Kajdaniuk2, Agata Urbanek³, Szymon Janyga ${ }^{3}$, \\ Aleksandra Bołdys' ${ }^{1}$,Marcin Basiak', Mateusz Maligłówka', Bogusław Okopień ${ }^{1}$ \\ ${ }^{1}$ Department of Internal Medicine and Clinical Pharmacology, Medical University of Silesia, Katowice, Poland \\ ${ }^{2}$ Department of Pathophysiology and Endocrinology, Medical University of Silesia, Zabrze, Poland \\ ${ }^{3}$ Department of Endocrinology and Diabetology, Regional Specialist Hospital, Rybnik, Poland
}

\begin{abstract}
Cardiovascular diseases are among the leading causes of increased morbidity and mortality in developed and developing countries. One of the most important risk factors responsible for atherosclerosis and subsequent cardiovascular diseases is hyperlipidaemia. Currently, hyperlipidaemias are divided into several clinical entities. The greatest risk is associated with hypercholesterolaemia. As a result, modern guidelines for the treatment and prevention of atherosclerosis focus predominantly on the reduction of LDL-cholesterol. Hypertriglyceridaemia and atherogenic dyslipidaemia, which are responsible for a less significant increase in the cardiovascular risk, are nowadays secondary targets of the treatment.

During the work-up for hyperlipidaemia one of the essential actions is the exclusion of secondary causes of the lipid abnormalities. Those include, among others, endocrine diseases, diabetes, drugs, nephrotic syndrome, and pregnancy. Data regarding the impact of endocrine disease and diabetes on the lipid profile are scattered. In this review, the authors aimed to perform a thorough analysis of the available publications regarding the topic and the preparation of a comprehensive review dealing with the incidence, clinical features, and the therapy of hyperlipidaemias in patients with endocrine disease. (Endokrynol Pol 2019; 70 (6): 511-452)
\end{abstract}

Key words: hypercholesterolaemia; hypertriglyceridaemia; hyperlipidaemia; endocrine disease; diabetes

\section{Introduction}

Lipid profile abnormalities are common in patients visiting general practitioners and endocrinologists, as well as in patients admitted to hospital wards. The importance of this finding is connected with significantly increased risk of atherosclerosis and its complications. Current treatment guidelines focus on the primary and secondary prevention of cardiovascular events and emphasise the importance of adherence to lipid-lowering strategies that consist of therapeutic lifestyle changes and pharmacotherapy [1]. Hyperlipidaemia is subdivided into several clinical subclasses: hypercholesterolaemia, hypertriglyceridaemia, mixed hyperlipidaemia, and atherogenic dyslipidaemia. The primary target for therapy is reduction of the LDL cholesterol (LDL-C) level, and the secondary aim concerns hypertriglyceridaemia. In referral units for treatment of refractory and severe hyperlipidaemias, a significant fraction of patients (nearly $30 \%$ ) have been found to be suffering from secondary hyperlipidaemias [2]. Therefore, during the clinical work-up, practitioners need to exclude secondary causes of lipid abnormalities. Those include: type 2 diabetes mellitus, alcohol abuse, and sev- eral endocrine disorders. Endocrine-related conditions, excluding diabetes (e.g. hypothyroidism, glucocorticoid excess, sex hormones excess, etc.) might be the cause of up to $13 \%$ of secondary hyperlipidaemias [2]. For many years it has been established that several endocrine diseases may worsen glucose tolerance or even lead to overt diabetes, but the topic of secondary hyperlipidaemias as a result of primary endocrine disease has not been profoundly explored. The most common endocrine causes of hyperlipidaemias are hypothyroidism, poorly controlled diabetes, and Cushing's syndrome. However, one should remember that there are also less common endocrine diseases that may be responsible for hyperlipidaemias, such as growth hormone deficiency, hyperparathyroidism. Hyperlipidaemia is a major risk factor for atherosclerosis, which in turn is responsible for increased cardiovascular mortality due to cardiovascular events (e.g. myocardial infarctions, strokes) [3]. Secondary hypertriglyceridaemia is connected with increased risk of acute pancreatitis [4]. The prevalence of hyperlipidaemias, certain specific features of lipid profiles, and additional risk of clinical problems resulting from untreated background endocrine disease led us to review the available data and provide a comprehensive 
summary on the topic of endocrine diseases as causes of secondary hyperlipidaemias.

\section{Characteristics of hyperlipidaemias}

The Frederickson classification of lipid disorders is considered as a reference in the diagnosis of hyperlipidaemias. It is based on the electrophoresis and centrifugation of serum, and defines six types of hyperlipidaemias [5]. However, in everyday clinical practice, due to its cumbersome methodology, it is rarely used. Nowadays a simplified approach, based on the measurement of fasting lipids [total cholesterol, triglycerides (TG), HDL-cholesterol (HDL-C), and LDL-cholesterol (LDL-C)], is routinely used. This clinical classification divides hyperlipidaemias into: predominant hypercholesterolaemia, predominant hypertriglyceridaemia, mixed hyperlipidaemia, and atherogenic hyperlipidaemia (Tab. I) [1]. The reasoning for that is based on results of clinical trials showing varying levels of cardiovascular risk connected with elevations of lipid fractions. Nowadays LDL-C is considered as a major participant in the progression of atherosclerosis and its complications. Cardiovascular events are responsible for a substantial proportion mortality among people overall. Therefore, the majority of efforts in the therapy of hyperlipidaemias are focused on elevated LDL-C. The priority of the LDL-C-lowering approach is changed toward hypertriglyceridaemia in patients with severely (> $500 \mathrm{mg} / \mathrm{dL}$ ) elevated triglycerides, which is based on the fact that such an elevation in triglycerides is a strong risk factor for a potentially fatal acute disease - acute pancreatitis. But one must remember that when the reduction of TG has been achieved (by proper therapeutic lifestyle change - TLC or diet), the target should be switched again toward LDL-C. In mixed hyperlipidaemia both TG and LDL-C are elevated, and, unless the concomitant TGs are $>500 \mathrm{mg} / \mathrm{dL}$, the LDL-C is a primary target. Atherogenic dyslipidaemia is a clinical entity that, at a first glance in lipid profile, seems like a mild mixed hyperlipidaemia. It is characterised by mild elevation in TG, low level of HDL ( $<40 \mathrm{mg} / \mathrm{dL}$ in males and $<50 \mathrm{mg} / \mathrm{dL}$ in females), and normal or slightly elevated LDL-C. In fact, these changes are more profound than they appear. It was shown that atherogenic dyslipidaemia is often developing in patients with concomitant insulin resistance, loss of lipoprotein lipase activity, and increased activity of CETP [6]. This leads to abnormalities in reverse cholesterol transfer from arteries (low HDL-C), a change in LDL-C particles that become severely atherogenic, and an increase in TG level. All these phenomena greatly accelerate atherosclerosis (Fig. 1).

When diagnosing hyperlipidaemias it is essential to make sure that the results obtained from the laboratory are valid. While the certification of the majority of laboratories greatly ensures clinicians that intra-laboratory errors should be minimised, more effort should be put on the pre-laboratory part, especially preparation of the patient for blood sampling. The patient should provide a fasting blood sample. The fasting status should be minimally $12 \mathrm{~h}$, preferably $16 \mathrm{~h}$. It is crucial especially in respect to $\mathrm{TG}$, which in some patients tends to be elevated for prolonged periods of time due to persistent postprandial chylomicronaemia [7].

\section{Endocrine disorders affecting lipid profile}

Endocrine disorders and poorly controlled diabetes are responsible for nearly a quarter of cases of hyperlipidaemia. Therefore, during the work-up of an abnormal lipid profile, efforts toward exclusion of endocrine causes should be made. In the following paragraphs a description of lipid abnormalities in endocrine disease is provided. The majority of such causes may be diagnosed or clinically suspected based on focused anamnesis and physical examination. In selected cases detailed laboratory studies should be considered, to confirm the diagnosis of secondary hyperlipidaemia.

\section{Hypothyroidism}

Thyroid hormones play an important role in the metabolism of lipids (Fig. 1). They increase the number of LDL receptors in the liver, increase synthesis of bile salts, reduce absorption of cholesterol from the GI tract, improve reverse cholesterol transfer from peripheral deposits (by the augmentation in ABCA1 and CETP), and increase the amount and activity of lipoprotein lipase and hepatic

Table I. Clinically important types of abnormal lipid profile

\begin{tabular}{|c|c|c|c|c|}
\hline Type of hyperlipidaemia & Total cholesterol & LDL-cholesterol & Triglycerides & HDL-cholesterol \\
\hline Hypercholesterolaemia & $\uparrow$ & $\uparrow$ & $\mathrm{N}$ & $\mathrm{N}$ \\
\hline Hypertriglyceridaemia & $\mathrm{N}$ & $\mathrm{N}$ & $\uparrow$ & $\mathrm{N}$ \\
\hline Mixed hyperlipidaemia & $\uparrow$ & $\uparrow$ & $\uparrow$ & $\mathrm{N}$ \\
\hline Atherogenic dyslipidaemia & $\uparrow / N$ & $\uparrow / N$ (small dense) & $\uparrow$ & $\downarrow$ \\
\hline
\end{tabular}

LDL — low density lipoprotein; HDL — high density lipoprotein 


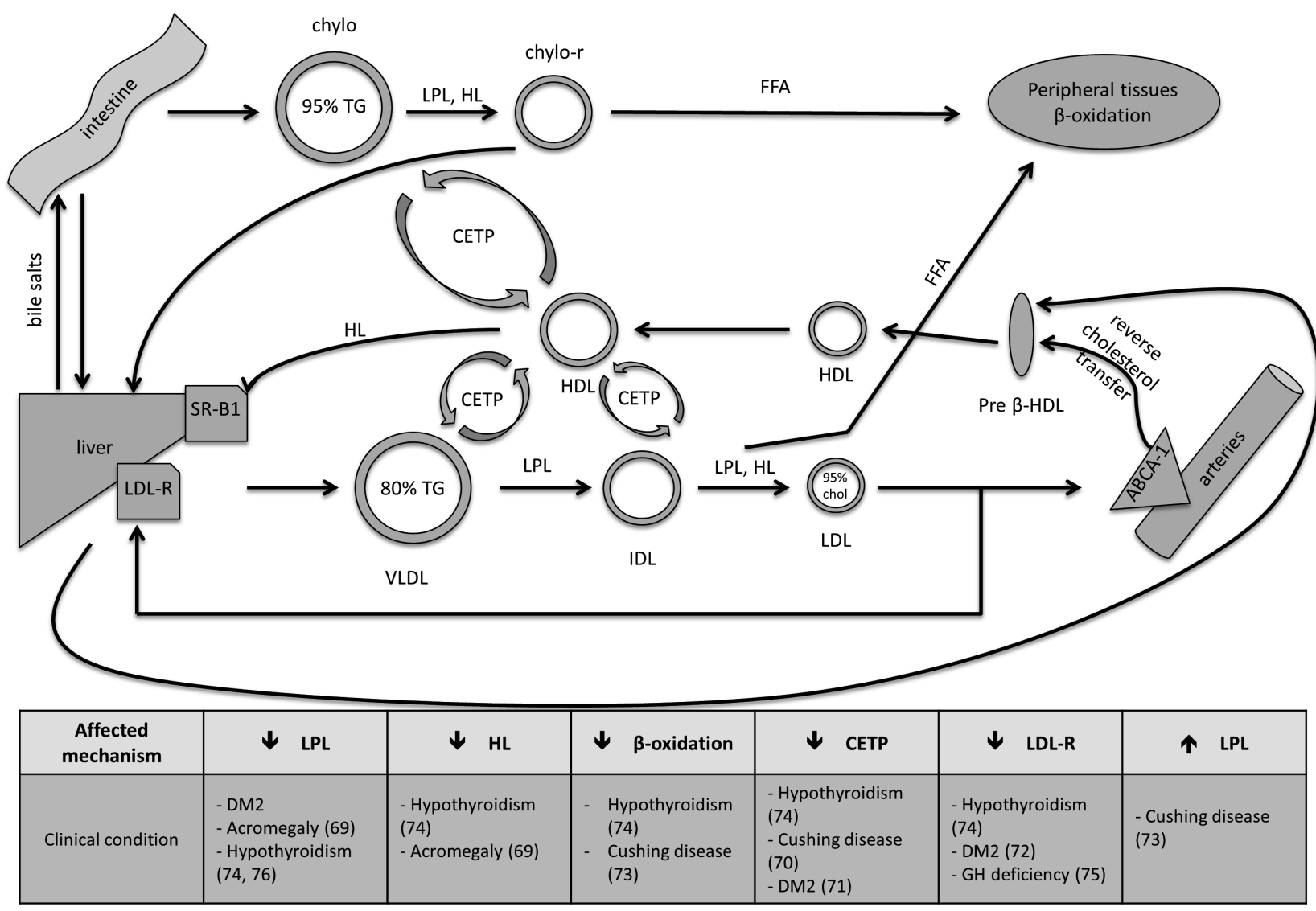

Figure 1. Schematic representation of metabolism of exogenous and endogenous lipids, which includes the involvement of enzymes and receptors that are affected in endocrine diseases. CETP — cholesterol esters transfer protein; chol — cholesterol, chylo — chylomicrones; chylo-r — chylomicron remnants; DM2 - type 2 diabetes mellitus; FFA — free fatty acids; GH — growth hormone; HDL — high-density lipoprotein; HL — hepatic lipase; IDL — intermediate-density lipoprotein; LDL — low-density lipoprotein; LDL-R — receptor for LDL; LPL — lipoprotein lipase; SR-B1 — scavenger receptor B1; TG — triglycerides [69-76]

lipase [8]. Therefore, significant elevations in total and LDL cholesterol (reaching 30\% compared to the healthy population) and less prominent rise in triglycerides are seen in patients with overt hypothyroidism. In patients with subclinical hypothyroidism the change in the lipid profile is generally not evident. The magnitude of lipid abnormalities correlates with TSH level. In some studies it was shown that even in euthyroid patients the TSH level correlates positively with total cholesterol, LDL-C, and triglycerides but negatively with HDL-C [9].

In patients with overt hypothyroidism, the introduction of treatment with levothyroxine has led to a reduction in total and LDL cholesterol and triglycerides. On the other hand, in patients with subclinical hypothyroidism, clinical data have shown less promising results [8]. Generally, in patients with TSH $>10 \mathrm{mIU} / \mathrm{L}$ the impact of levothyroxine on abnormal lipid profile is clear, which is concordant with other studies showing greater benefit in this group of patients with subclinical hypothyroidism [10].

Nowadays, it seems reasonable to perform TSH estimation in all patients with hyperlipidaemia on a regular basis because hypothyroidism, especially subclinical, is a relatively common disease (1.4-11.2\% of the population) [11], may negatively affects patients' quality of life, and might be a cause of increased morbidity [10]. What is more, the treatment of the disease is generally well tolerated, not cumbersome, and, especially in people with overt hypothyroidism, it improves the lipid profile. However, the normalisation of the lipid profile may not be achieved during the therapy with levothyroxine, which may be the result of background hyperlipidaemia. In such cases, a specific, lipid-lowering therapy should be introduced. In the majority of cases the drug of choice is a statin. Due to the increased risk of rhabdomyolysis, the initiation of lipid-lowering therapy with statins is not recommended until euthyreosis is achieved [12].

\section{Hyperthyroidism}

Hyperthyroidism is not the cause of hyperlipidaemia, but a very low LDL-C level, especially with signs and symptoms of hyperthyroidism, should urge clinicians to exclude subclinical or overt hyperparathyroidism. 
Despite lipid-lowering effects of the excess of thyroid hormones, patients' overall prognosis is worsened [13].

\section{Poorly controlled diabetes}

Contrary to hypothyroidism, uncontrolled diabetes leads to hypertriglyceridaemia and features of atherogenic dyslipidaemia [14]. Despite statin therapy, it is estimated that as many as $50 \%$ of patients with diabetes have increased level of TG [15]. This results from multiple factors. Generally, patients with bad glycaemic control do not adhere to an appropriate diet, which in many cases contains simple carbohydrates and saturated fats. Dietary fat is transported from the intestines in triglyceride-rich chylomicrons, responsible for a high level of postprandial triglycerides. In the liver, due to an excess of food and insulin resistance, the increased synthesis of TG and its excretion in VLDL is also seen. The TG level is further augmented by the loss of activity in LPL due to increased production of apoCIII (a physiological inhibitor of LPL). What is more, due to alterations in lipid transfer by CETP, LDL cholesterol particles in those patients become very atherogenic - "small dense LDLs" [16]. Finally, in patients with significantly elevated glycaemia, an ongoing glycation and oxidation of lipoproteins is responsible for the acceleration of atherosclerosis and its complications [17].

Hypertriglyceridaemia, especially with concurrent atherogenic dyslipidaemia, is a known risk factor for cardiovascular diseases [18]. Therefore, it should be treated according to standards of care. The primary goal of therapy is still the LDL-C level, and TG is considered as a second-line treatment goal. In patients with diabetes the treatment of hyperlipidaemia must be multidirectional. A proper therapeutic lifestyle change (TLC), including regular physical activity and diet, is essential. As a result, LDL cholesterol can be reduced by around $10-15 \%$ after TLC [19]. Currently, it is recommended to reduce LDL-C in patients with type 2 diabetes below $70 \mathrm{mg} / \mathrm{dL}$. Therefore, in many cases cholesterol-lowering therapy should be introduced at the initial visit. TG level below $500 \mathrm{mg} / \mathrm{dL}$ may be initially dealt with by a three-month watch-and-wait strategy for the effects of TLC ( \pm statin). Due to a proper diet, physical activity, and in some cases statin use, remarkable improvements in lipid profile are seen [20]. Conversely, the treatment with fibrates and/or omega-3 fatty acids should be immediately introduced in severe hypertriglyceridaemia (> $500 \mathrm{mg} / \mathrm{dL}$ ) or the lack of benefit after TLC or statins.

\section{Cushing's disease}

Compared to hypothyroidism and diabetes, secondary hyperlipidaemia due to elevated, autonomous secretion of glucocorticoids is much less common. On the other hand, $52 \%$ of patients with hypercortisolism are affected by secondary lipid abnormalities [21]. It may be seen more often as the result of the treatment with glucocorticoids (as immunosuppressive agents or excessive substitution). The risk of developing cardiovascular complications is increased even in subjects with "non-functional" adrenal tumours. It was shown that the higher the level of cortisol in $1 \mathrm{mg}$ dexamethasone suppression test (all results within $<1.8 \mathrm{ug} / \mathrm{dL}$ ), the higher the likelihood of developing diabetes [adjusted $\mathrm{RR}=1.87(1.17,2.98)$ ] [22]. The cardiovascular risk is additionally elevated in the group with subclinical hypercortisolism [23]. In respect to the lipid profile, glucocorticoids tend to cause atherogenic dyslipidaemia (high TG and low LDL-C), which is commonly connected with central obesity and metabolic syndrome [24].

Naturally, the treatment of choice is the elimination of hypercortisolism. This can be best achieved by the surgical resection of adrenal or pituitary adenoma (especially in overt hypercortisolism) or fine-tuning the cortisol replacement therapy. As a result, a significant improvement, but generally not normalisation, in the lipid profile, described by reductions in TG and LDL-C and an increase in HDL-C, can be achieved [21]. When curative treatment is not possible, a general approach to treat hypercortisolism, including ketoconazole or mitotane, is introduced. Additionally, significant effort should be focused on the reduction of cardiovascular risk factors. Therefore, a therapeutic lifestyle change is advised. In the majority of cases, the treatment of atherogenic dyslipidaemia must include pharmacotherapy. All standard groups of drugs can be used, depending on the mostly elevated lipoprotein fraction (statins in predominant hypercholesterolaemia and fibrates in predominant hypertriglyceridaemia). It should be kept in mind that in patients treated with ketoconazole, which is a potent cytochrome P450 inhibitor, clinically significant drug interactions with lipid-lowering drugs may occur. In the necessity of combined therapy with ketoconazole and statins, pravastatin should be used as the drug of choice. Additionally, in cases of suspected Cushing's syndrome in patients on lipid-lowering therapy, one should consider cessation of fibrate, because in specific circumstances it can lead to false positive diagnosis of hypercortisolism. Fenofibrate interferes with the assay of free cortisol from urine specimens. If the drug cannot be withdrawn, other confirmatory tests for hypercortisolism should be selected [25].

\section{Pituitary diseases}

\section{Hyperprolactinaemia}

Hyperprolactinaemia affects various aspects of lipid and glucose metabolism and leads to atherogenic dyslipidaemia, primarily with elevated triglycerides and 
LDL-C [26]. The influence on the lipid profile results mainly from the inhibitory effect of prolactin on LPL [27]. Additionally, with the increase in the diameter of adenoma subsequent failure of the pituitary gland occurs, leading to GH deficiency, hypogonadism, and, in severely advanced disease, to hypothyroidism, which are responsible for augmentation of lipid abnormalities. Interestingly, it was noted that in female patients with macroprolactinaemia the HDL-C level is decreased by around 11\% compared to healthy women [28]. The therapy of hyperprolactinaemia with dopamine agonists is effective also in the improvement of lipid profile. Total cholesterol and LDL-cholesterol have been significantly reduced following such a therapy [29]. In patients with increased level of TG, further improvements may be achieved by the addition of fenofibrate to the therapy [30].

\section{Acromegaly}

Different kinds of lipid abnormalities are diagnosed in $33 \%$ of patients with acromegaly [31]. According to data from small-sample observatory studies, $19-56 \%$ of patients with acromegaly had increased level of triglycerides, which is significantly more than among age-matched individuals $[32,33]$. Conversely, the cholesterol level is generally mildly elevated in the course of the disease [34]. It seems that the elevated TG level is connected with increased synthesis of fatty acids and reduced activity of LPL [35]. This results in the elevation of triglyceride level, which may trigger acute pancreatitis, which is occasionally seen in such patients. Additional risk factors that may aggravate hyperlipidaemia are hormonal insufficiencies of other pituitary endocrine axes (e.g. secondary hypothyroidism, hypogonadism), which are caused by compression trauma in macroadenomas. Lipid abnormalities in patients with acromegaly were shown to be responsible for accelerated progression of subclinical atherosclerosis (intima media thickness and pulse-wave velocity), which in turn may be responsible for increased cardiovascular risk [36]. It was also noted that the risk of cardiovascular complication is considerably elevated and correlates positively with the duration of acromegaly [37].

The greatest improvements in lipid profile are observed in patients after successful surgical treatment of adenoma. Subsequently, the lipid profile improves significantly, which is reflected by a drop in TG concentration. In a paper showing a series of cases of surgically treated patients, the reduction in TG level reached 50.7\% ( $p=0.004)$ [38]. The improvement during the treatment of acromegaly is strictly related to the achieved reduction in $\mathrm{GH}$, which leads to increased activity of LPL and finally to the reduction of TG [39, 40]. Recent clinical trials have shown that the lipid profile improvements are the result of the achievement of control of the disease. Somatostatin analogues have led to significant reductions in TG level, which was accompanied by a rise in HDL-C [41]. Lipid abnormalities that are concurrent with acromegaly should be treated according to general guidelines in the treatment of hyperlipidaemias. Therefore, after cardiovascular risk estimation, treatment with statins or fibrate should be introduced. In the case of patients on somatostatin analogues, prior to the introduction of fibrate, gallstones should be excluded. Fibrates are contraindicated in those patients due to increased cholesterol content in bile, which is responsible for increased propensity for gallstone formation [42].

\section{Growth hormone deficiency}

In children, growth hormone deficiency leads to growth retardation. The majority of patients are withdrawn from the GH substitution on entering adulthood or when satisfactory height is achieved. Interestingly, adult patients with GH deficiency in many countries have been on hormone replacement therapy to prevent metabolic complication for the last 30 years [43]. The incidence of metabolic syndrome in adult patients with GH deficiency is more than doubled compared to healthy subjects (38.0 vs. $15.7 \%, \mathrm{p}<0.0001)$ [44]. Detailed analysis of the lipid profiles of those patients revealed significantly elevated LDL-C and TG (in 85\% and $44 \%$ of patients, respectively), which were often accompanied by a reduction in HDL-C (in $47 \%$ of patients) [45]. Such a lipid profile should be considered as atherogenic dyslipidaemia.

GH replacement therapy in children has shown improvements in lipid profile, which may prevent atherogenic complications in the future [46]. However, the improvements in lipid profile in adults are less evident, showing persistent atherogenic dyslipidaemia during up to five years of the treatment or only minor $(5 \%)$ reduction in total cholesterol [47]. Interestingly, in patients following effective treatment for acromegaly, who developed GH deficiency, GH replacement therapy seemed to improve lipid profile [48]. In conclusion, the impact of GH itself on lipid profile and long-term benefits in adults are less clear [49]. Therefore, it seems that the active treatment of dyslipidaemia with hypolipidemic drugs should be introduced according to the estimated cardiovascular risk or concomitant diseases to prevent further atherosclerotic complications.

\section{Combined pituitary hormone deficiency}

Combined pituitary hormone deficiency (CPHD) is diagnosed when there is a deficiency or absence of at least two pituitary hormones. The genetic background relies 
on mutations of several proteins associated with the development of pituitary gland and subsequent secretion of hormones (e.g. Pit-1, PROP-1). Clinical manifestations may vary, depending on major hormone deficiencies, but a rise in total cholesterol and LDL-C is commonly seen [50]. The most probable cause of hypercholesterolaemia in those cases is secondary hypothyroidism. Therefore, successful treatment of hypothyroidism generally leads to the normalisation of cholesterol level. Naturally, in those specific and rare cases, prior to the administration of levothyroxine, a secondary adrenal gland insufficiency must be excluded.

On the other hand, in patients suffering from Sheehan's syndrome, various hyperlipidaemias have been diagnosed, which were connected with the reduced level of lipoprotein lipase and hepatic lipase activity [51]. Reduced activity of both lipases is responsible for various forms of hyperlipidaemias with predominant hypertriglyceridaemia. The introduction of proper hormonal substitution with hydrocortisone and levothyroxine resulted in the reconstitution of lipase activity and normalisation of lipid profile.

\section{Polycystic ovary syndrome}

Polycystic ovary syndrome (PCOS) may affect up to $20 \%$ of the population of otherwise healthy females. The majority of clinical problems that lead to seeking for help result from infertility and patients changed body appearance due to hyperandrogenaemia. However, due to androgen excess those patients suffer from atherogenic dyslipidaemia [52]. The greatest benefits can be achieved by therapeutic lifestyle change leading to reduced body weight and increased physical activity. Some lipid benefits (reduction in LDL-C and TG) are seen after the introduction of metformin [53]. In the older population or in those with additional cardiovascular risk factors, targeted treatment of lipid abnormalities can be offered. Nevertheless, it should be noted that statin therapy may worsen glucose sensitivity in this specific vulnerable population [54].

\section{Oestrogen/progesterone excess and oral contraception}

Combined oral contraception (COC) and progestin-only oral contraception (POC) are methods of contraception used by around 13\% of women [55]. Combined oral contraception has been shown to increase triglyceride and total cholesterol (mainly by an increase in HDL-C), whereas POC seemed to have neutral impact on lipid profile. COCs are contraindicated in severe dyslipidaemia, especially in patients with elevated TG, due to the increased risk of acute pancreatitis. In this clinical setting intrauterine devices should be recommended [56].

\section{Hypogonadism}

Male hypogonadism may arise from testicular damage (primary hypogonadism) or as a consequence of hypothalamic-pituitary axis insufficiency (secondary hypogonadism). The diagnosis is generally made by the presence of clinical signs and symptoms with concurrent low level of testosterone taken on several occasions [57]. Nowadays, a substantial group of patients, due to obesity, develop secondary hypogonadism [58]. Obesity and metabolic syndrome lead to a mild atherogenic dyslipidaemia. Testosterone replacement therapy improves patients' quality of life and glucose metabolism, but its impact on the lipid profile is less apparent. Reductions in total cholesterol and TG are minute (generally < 5\%) [59, 60]. During the therapy, improvements in markers of cardiovascular diseases (e.g. apoB) have been noted [61], but the impact on cardiovascular outcomes remains inconclusive due to the lack of data of sufficient quality [62].

In postmenopausal women, a tendency toward increased levels of total cholesterol and LDL-C triglycerides, and reduced level of HDL-C has been noted [63]. The LDL-C level is increased in more than $48 \%$ of patients, low HDL-C level is seen in more than $42 \%$ of patients, and high TG in nearly $30 \%$ of patients. Lipid profile abnormalities and additional metabolic changes (obesity, arterial hypertension, and insulin resistance) lead to increased risk of cardiovascular events [64]. Despite the change in lipid profile that is attributed to ovarian failure, hormone replacement therapy with oestrogen and progesterone has not reduced the cardiovascular risk and markers of subclinical atherosclerosis in postmenopausal women [65]; nowadays it is not recommended in cardiovascular prevention but merely for symptomatic relief. Therefore, in postmenopausal women with abnormal lipid profile a targeted hypolipidemic therapy (e.g. statin, fibrate) should be introduced.

\section{Hyperparathyroidism}

In patients with primary and secondary hyperparathyroidism, a predominant increase in TG level has been noted. More than $52 \%$ of patients suffer from some sort of hyperlipidaemia [66], which is 50\% higher than the incidence of hyperlipidaemia in the population from the same background. The reason for that is not fully understood, but patients with hyperparathyroidism more often suffer from obesity and diabetes, which may be related to reduced physical activity. However, it has also been shown that the TG level rapidly dropped in patients with primary hyperparathyroidism as soon as seven days after surgery of parathyroid adenoma $(1.50 \pm 0.11$ to $1.19 \pm 0.07 \mathrm{mmol} / \mathrm{L} ; \mathrm{p}<0.001)$ and has been maintained at a lower level for up to 12 months 
Table II. Lipid profile abnormalities in endocrine disorders

\begin{tabular}{lcccc}
\hline Clinical condition & Total cholesterol & LDL-cholesterol & Triglycerides & HDL-cholesterol \\
\hline Hypothyroidism & $\uparrow$ & $\uparrow$ & & \\
\hline DM2 & $\uparrow / N$ & $\uparrow / N$ (small dense) & $\uparrow$ & $\downarrow$ \\
\hline Hypercortisolism & $\uparrow / N$ & $\uparrow / N$ & $\uparrow$ & $\downarrow$ \\
\hline Hyperprolactinaemia & $\uparrow$ & $\uparrow$ & $\uparrow$ & \\
\hline Acromegaly & $\uparrow / N$ & $\uparrow$ & \\
\hline GH deficiency & $\uparrow$ & $\uparrow / N$ & \\
\hline CPHD & $\uparrow$ & $\uparrow$ & $\uparrow$ & \\
\hline PCOS & $\uparrow$ (small dense) & $\uparrow$ & \\
\hline O/P excess or oral contraception & & $\uparrow$ & $\downarrow / N$ \\
\hline Hypogonadism & $\uparrow / N$ & $\uparrow$ & $\downarrow$ \\
\hline Hyperparathyroidism & & $\uparrow$ & \\
\hline
\end{tabular}

CPHD — combined pituitary hormone deficiency; DM2 — type 2 diabetes mellitus; PCOS — polycystic ovary sendrome; 0/P — oestrogen/progestin; GH — growth hormone; LDL — low density lipoprotein; HDL — high density lipoprotein

of follow-up $(1.17 \pm 0.11 \mathrm{mmol} / \mathrm{L})$ [67]. On the other hand, other researchers have shown that parathyroidectomy did not lead to any significant change in lipid profile [68]. The differences in favour of non-surgically treated patients have been attributed to lipid-lowering therapy. Therefore, the curative method in the treatment of hyperthyroidism is a surgical approach, but it is indicated in patients with clinical or laboratory features that support such treatment. On the other hand, in patients who are not treated operatively, a mild increase in TG or LDL-C level can be successfully treated with lipid-lowering drugs.

\section{Conclusions}

Endocrine disorders are relatively common causes of secondary hyperlipidaemia. The wide variety of lipid profile abnormalities makes it nearly impossible to specifically suspect endocrine disease (Tab. II). However, due to the fact that the thyroid function abnormalities and hypercholesterolaemia are often seen in the general population, it is recommended to exclude hypothyroidism in every patient with hypercholesterolaemia (generally, TSH measurement is sufficient). Due to strict recommendations regarding LDL-C levels, the lipid profile in patients with type 2 diabetes is generally regularly checked concomitantly to markers of glucose control $\left(\mathrm{HbA}_{1 \mathrm{c}}\right)$. Therefore, worsening of lipid profile may swiftly be correlated with glucose levels and proper diet or using pharmacological therapy. In the majority of hyperlipidaemias, the suspicion of endocrine disease should be based on a clinical approach rather than on simple lipid profile estimation (e.g. red stretch marks in Cushing's disease or reduced sexual drive in hypogonadism). The treatment of secondary hyperlipidaemias in many cases is focused on the offending endocrine disease, but in the majority of cases it must be strengthened by specific lipid lowering therapy.

\section{Conflict of interests}

All authors state that they have no financial interest in the subject matter or materials discussed in this manuscript.

\section{Funding}

The study was supported by a research grant from Medical University of Silesia (KNW-1-095/N/8/0).

\section{References}

1. Catapano AL, Graham I, De Backer G, et al. ESC Scientific Document Group. 2016 ESC/EAS Guidelines for the Management of Dyslipidaemias. Eur Heart J. 2016; 37(39): 2999-3058, doi: 10.1093/eurheartj/ehw272, indexed in Pubmed: 27567407.

2. Vodnala D, Rubenfire M, Brook RD. Secondary causes of dyslipidemia Am J Cardiol. 2012; 110(6): 823-825, doi: 10.1016/j.amjcard.2012.04.062, indexed in Pubmed: 22658245.

3. O'Keefe JH, Cordain L, Harris WH, et al. Optimal low-density lipoprotein is 50 to $70 \mathrm{mg} / \mathrm{dl}$ : lower is better and physiologically normal. J Am Coll Cardiol. 2004; 43(11): 2142-2146, doi: 10.1016/j.jacc.2004.03.046, indexed in Pubmed: 15172426.

4. Carr RA, Rejowski BJ, Cote GA, et al. Systematic review of hypertriglyceridemia-induced acute pancreatitis: A more virulent etiology? Pancreatology. 2016; 16(4): 469-476, doi: 10.1016/j.pan.2016.02.011, indexed in Pubmed: 27012480.

5. Fredrickson DS, LEES RS. A system for phenotyping hyperlipoproteinemia. Circulation. 1965; 31:321-327, doi: 10.1161/01.cir.31.3.321, indexed in Pubmed: 14262568.

6. Hirano T. Pathophysiology of Diabetic Dyslipidemia. J Atheroscler Thromb. 2018; 25(9): 771-782, doi: 10.5551/jat.RV17023, indexed in Pubmed: 29998913.

7. Nigam PK. Serum Lipid Profile: Fasting or Non-fasting? Indian J Clin Biochem. 2011; 26(1): 96-97, doi: 10.1007/s12291-010-0095-x, indexed in Pubmed: 22211025.

8. Pearce EN. Update in lipid alterations in subclinical hypothyroidism. J Clin Endocrinol Metab. 2012; 97(2): 326-333, doi: 10.1210/jc.2011-2532, indexed in Pubmed: 22205712.

9. Asvold BO, Vatten LJ, Nilsen TIL, et al. The association between $\mathrm{TSH}$ within the reference range and serum lipid concentrations in a population-based study. The HUNT Study. Eur J Endocrinol. 2007; 156(2): 181-186, doi: 10.1530/eje.1.02333, indexed in Pubmed: 17287407. 
10. Cojić M, Cvejanov-Kezunović L. Subclinical Hypothyroidism - Whether and When To Start Treatment? Open Access Maced J Med Sci. 2017; 5(7): 1042-1046, doi: 10.3889/oamims.2017.195, indexed in Pubmed: 29362642.

11. Ineck BA, $\mathrm{Ng} \mathrm{TMH}$. Effects of subclinical hypothyroidism and its treatment on serum lipids. Ann Pharmacother. 2003; 37(5): 725-730, doi: 10.1345/aph.1C376, indexed in Pubmed: 12708952

12. Tokinaga $\mathrm{K}$, Oeda T, Suzuki $\mathrm{Y}$, et al. HMG-CoA reductase inhibitors (statins) might cause high elevations of creatine phosphokinase (CK) in patients with unnoticed hypothyroidism. Endocr J. 2006; 53(3): 401-405, doi: 10.1507/endocri.k04-144, indexed in Pubmed: 16723812.

13. Andrikoula M, Avades T. Hypolipidaemia is not always indicating liver dysfunction. A review of primary and secondary high density lipoprotein and low density lipoprotein deficiencies. Minerva Med. 2006; 97(6): 487-494, indexed in Pubmed: 17213785.

14. Patti AM, Giglio RV, Papanas N, et al. Future perspectives of the pharmacological management of diabetic dyslipidemia. Expert Rev Clin Pharmacol. 2019; 12(2): 129-143, doi: 10.1080/17512433.2019.1567328, indexed in Pubmed: 30644763

15. Feher M, Greener M, Munro N. Persistent hypertriglyceridemia in statin-treated patients with type 2 diabetes mellitus. Diabetes Metab Syndr Obes. 2013; 6: 11-15, doi: 10.2147/DMSO.S35053, indexed in Pubmed: 23341741.

16. Pang J, Chan DC, Watts GF. Origin and therapy for hypertriglyceridaemia in type 2 diabetes. World J Diabetes. 2014; 5(2): 165-175, doi: 10.4239/wjd. v5.i2.165, indexed in Pubmed: 24748930.

17. Katakami N. Mechanism of Development of Atherosclerosis and Cardiovascular Disease in Diabetes Mellitus. J Atheroscler Thromb. 2018; 25(1): 27-39, doi: 10.5551/jat.RV17014, indexed in Pubmed: 28966336.

18. Okopien B, Buldak L, Bołdys A. Fibrates in the management of atherogenic dyslipidemia. Expert Rev Cardiovasc Ther. 2017; 15(12): 913-921, doi: 10.1080/14779072.2017.1408410, indexed in Pubmed: 29183206.

19. Lichtenstein AH, Ausman LM, Jalbert SM, et al. Efficacy of a Therapeutic Lifestyle Change/Step 2 diet in moderately hypercholesterolemic middle-aged and elderly female and male subjects. J Lipid Res. 2002; 43(2): 264-273, indexed in Pubmed: 11861668.

20. Miller M, Stone NJ, Ballantyne C, et al. American Heart Association Clinical Lipidology, Thrombosis, and Prevention Committee of the Council on Nutrition, Physical Activity, and Metabolism, Council on Arteriosclerosis, Thrombosis and Vascular Biology, Council on Cardiovascular Nursing, Council on the Kidney in Cardiovascular Disease. Triglycerides and cardiovascular disease: a scientific statement from the American Heart Association. Circulation. 2011; 123(20): 2292-2333, doi: 10.1161/CIR.0b013e3182160726, indexed in Pubmed: 21502576.

21. Greenman Y. Management of dyslipidemia in Cushing's syndrome. Neuroendocrinology. 2010; 92 Suppl 1: 91-95, doi: 10.1159/000314294, indexed in Pubmed: 20829626.

22. Lopez D, Luque-Fernandez MA, Steele A, et al. "Nonfunctional" Adrenal Tumors and the Risk for Incident Diabetes and Cardiovascular Outcomes: A Cohort Study. Ann Intern Med. 2016; 165(8): 533-542, doi: 10.7326/M16-0547, indexed in Pubmed: 27479926.

23. Tauchmanovà L, Rossi R, Biondi B, et al. Patients with subclinical Cushing's syndrome due to adrenal adenoma have increased cardiovascular risk. J Clin Endocrinol Metab. 2002; 87(11): 4872-4878, doi: 10.1210/jc.2001-011766, indexed in Pubmed: 12414841.

24. Anagnostis $\mathrm{P}$, Athyros VG, Tziomalos $\mathrm{K}$, et al. Clinical review: The pathogenetic role of cortisol in the metabolic syndrome: a hypothesis. J Clin Endocrinol Metab. 2009; 94(8): 2692-2701, doi: 10.1210/jc.2009-0370, indexed in Pubmed: 19470627.

25. Meikle AW, Findling J, Kushnir MM, et al. Pseudo-Cushing syndrome caused by fenofibrate interference with urinary cortisol assayed by high-performance liquid chromatography. J Clin Endocrinol Metab. 2003; 88(8): 3521-3524, doi: 10.1210/jc.2003-030234, indexed in Pubmed: 12915630.

26. Perić B, Kruljac I, Šundalić S, et al. Obesity and hypercholesterolemia in patients with prolactinomas: Could DHEA-S and growth hormone be the missing link? Endocr Res. 2016; 41(3): 200-206, doi: 10.3109/0743 5800.2015.1135444, indexed in Pubmed: 26864960.

27. Ling C, Svensson L, Odén B, et al. Identification of functional prolactin (PRL) receptor gene expression: PRL inhibits lipoprotein lipase activity in human white adipose tissue. J Clin Endocrinol Metab. 2003; 88(4): 1804-1808, doi: 10.1210/jc.2002-021137, indexed in Pubmed: 12679477.

28. Krysiak R, Marek B, Okopień B. Cardiometabolic risk factors in young women with macroprolactinaemia. Endokrynol Pol. 2019; 70(4): 336-341, doi: 10.5603/EP.a2019.0013, indexed in Pubmed: 30845340

29. Berinder $K$, Nyström T, Höybye $C$, et al. Insulin sensitivity and lipid profile in prolactinoma patients before and after normalization of prolactin by dopamine agonist therapy. Pituitary. 2011; 14(3): 199-207, doi: 10.1007/s11102-010-0277-9, indexed in Pubmed: 21128120.

30. Krysiak R, Szkróbka W, Okopień B. Different effects of fenofibrate on cardiometabolic risk factors in young women with and without hyperprolactinemia. Pharmacol Rep. 2019; 71(1): 61-66, doi: 10.1016/j. pharep.2018.09.004, indexed in Pubmed: 30469130.
31. Woodmansee WW, Gordon MB, Molitch ME, et al. Screening for comorbid conditions in patients enrolled in the SODA registry: a 2-year observational analysis. Endocrine. 2018; 61(1): 105-117, doi: 10.1007/s12020-018-1615-3, indexed in Pubmed: 29767287.

32. Tsuchiya H, Onishi T, Mogami H, et al. Lipid metabolism in acromegalic patients before and after selective pituitary adenomectomy. Endocrinol Jpn. 1990; 37(6): 797-807, doi: 10.1507/endocrj1954.37.797, indexed in Pubmed: 2129301.

33. Ioanițiu D, Bartoc R, Ispas I, et al. The dyslipemic syndrome in acromegaly. Endocrinologie. 1982; 20(1): 25-36, indexed in Pubmed: 7041236.

34. Nikkilä EA, Pelkonen R. Serum lipids in acromegaly. Metabolism. 1975; 24(7): 829-838, doi: 10.1016/0026-0495(75)90129-8, indexed in Pubmed: 1138157.

35. Takeda R, Tatami R, Ueda K, et al. Secondary type V hyperlipoproteinemia in an acromegalic patient without overt diabetes. Endokrinologie. 1982; 79(1): 140-148, indexed in Pubmed: 7084127.

36. Cansu GB, Yılmaz N, Yanıkoğlu A, et al. Assessment of diastolic dysfunction, arterial stiffness, and carotid intima-media thickness in patients with acromegaly. Endocr Pract. 2017; 23(5): 536-545, doi: 10.4158/EP161637.OR, indexed in Pubmed: 28156155

37. Golkowski F, Krzentowska-Korek A, Baldys-Waligorska A, et al. Goiter cardiovascular and metabolic disorders in patients with acromegaly. Endocr Regul. 2011; 45(4): 191-197, indexed in Pubmed: 22073948.

38. Tsuchiya $\mathrm{H}$, Onishi T, Mogami $\mathrm{H}$, et al. Lipid metabolism in acromegalic patients before and after selective pituitary adenomectomy. Endocrinol Jpn. 1990; 37(6): 797-807, doi: 10.1507/endocrj1954.37.797, indexed in Pubmed: 2129301.

39. Takeda R, Tatami R, Ueda $\mathrm{K}$, et al. The incidence and pathogenesis of hyperlipidaemia in 16 consecutive acromegalic patients. . Acta Endocrinol (Copenh). 1982; 100 (3): 358-362, doi: 10.1507/endocrj1954.37.797, indexed in Pubmed: 2129301.

40. Takeda R, Tatami R, Ueda K, et al. Secondary type V hyperlipoproteinemia in an acromegalic patient without overt diabetes. Endokrinologie. 1982; 79(1): 140-148, indexed in Pubmed: 7084127.

41. Caron PI, Petersenn S, Houchard A, et al. PRIMARYS Study Group. Glucose and lipid levels with lanreotide autogel $120 \mathrm{mg}$ in treatment-naïve patients with acromegaly: data from the PRIMARYS study. Clin Endocrinol (Oxf). 2017; 86(4): 541-551, doi: 10.1111/cen.13285, indexed in Pubmed: 27874199.

42. Preiss D, Seshasai SR, Welsh P, et al. Risk of incident diabetes with intensive-dose compared with moderate-dose statin therapy: a meta-analysis. JAMA. 2011; 305(24): 2556-2564, doi: 10.1001/jama.2011.860, indexed in Pubmed: 21693744.

43. Lewiński A, Smyczyńska J, Stawerska R, et al. National Program of Severe Growth Hormone Deficiency Treatment in Adults and Adolescents after Completion of Growth Promoting Therapy. Endokrynol. Pol. 2018; 69(5): 468-524, doi: 10.5603/ep.a2018.0054, indexed in Pubmed: 30117531.

44. van der Klaauw AA, Biermasz NR, Feskens EJM, et al. The prevalence of the metabolic syndrome is increased in patients with GH deficiency, irrespective of long-term substitution with recombinant human GH. Eur J Endocrinol. 2007; 156(4): 455-462, doi: 10.1530/EJE-06-0699, indexed in Pubmed: 17389460.

45. Itoh E, Hizuka N, Fukuda I, et al. Metabolic disorders in adult growth hormone deficiency: A study of 110 patients at a single institute in Japan. Endocr J. 2006; 53(4): 539-545, doi: 10.1507/endocrj.k03-115, indexed in Pubmed: 16829702

46. Kohno H, Tanaka T, Fujieda K, et al. Favorable Impacts of Growth Hormone (GH) Replacement Therapy on Atherogenic Risks in Japanese Children with GH Deficiency. Clin Pediatr Endocrinol. 2012; 21(2): 15-20, doi: 10.1297/cpe.21.15, indexed in Pubmed: 23926406.

47. Shimatsu A, Tai S, Imori M, et al. Efficacy and safety of growth hormone replacement therapy in Japanese adults with growth hormone deficiency: a post-marketing observational study. Endocr J. 2013; 60(10): 1131-1144, doi: 10.1507/endocrj.ej13-0083, indexed in Pubmed: 23823978

48. Norrman LL, Johannsson G, Sunnerhagen KS, et al. Baseline characteristics and the effects of two years of growth hormone $(\mathrm{GH})$ replacement therapy in adults with GH deficiency previously treated for acromegaly. J Clin Endocrinol Metab. 2008; 93(7): 2531-2538, doi: 10.1210/jc.2007-2673, indexed in Pubmed: 18397981.

49. Claessen KM, Appelman-Dijkstra NM, Pereira AM, et al. Abnormal metabolic phenotype in middle-aged GH-deficient adults despite long-term recombinant human GH replacement. Eur J Endocrinol. 2014; 170(2): 263-272, doi: 10.1530/EJE-13-0764, indexed in Pubmed: 24217935

50. Andrikoula M, Sertedaki A, Andrikoula S, et al. PROP-1 gene mutation in a 63-year-old woman presenting with osteoporosis and hyperlipidaemia. Hormones (Athens). 2013; 12(1): 128-134, doi: 10.1007/BF03401294, indexed in Pubmed: 23624138.

51. Ishibashi S, Murase T, Yamada N, et al. Hyperlipidaemia in patients with hypopituitarism. Acta Endocrinol (Copenh). 1985; 110(4): 456-460, doi: 10.1530/acta. 0.1100456 , indexed in Pubmed: 4090908. 
52. Dutkowska A, Konieczna A, Breska-Kruszewska J, et al. [Recomendations on non-pharmacological interventions in women with PCOS to reduce body weight and improve metabolic disorders [Zalecenia dotyczace postępowania niefarmakologicznego u kobiet z PCOS celem zmniejszenia masy ciała i poprawy zaburzeń metabolicznych] Endokrynol Pol. 2019; 70(2): 198-212, doi: 10.5603/EP.a2019.0006, indexed in Pubmed: 31039273.

53. Milewicz A, Kudła M, Spaczyński RZ, et al. The polycystic ovary syndrome: a position statement from the Polish Society of Endocrinology, the Polish Society of Gynaecologists and Obstetricians, and the Polish Society of Gynaecological Endocrinology. Endokrynol Pol. 2018; 69(4), doi: 10.5603/EP.2018.0046, indexed in Pubmed: 30209800.

54. Puurunen J, Piltonen T, Puukka K, et al. Statin therapy worsens insulin sensitivity in women with polycystic ovary syndrome (PCOS): a prospective, randomized, double-blind, placebo-controlled study. J Clin Endocrinol Metab. 2013; 98(12): 4798-4807, doi: 10.1210/jc.2013-2674, indexed in Pubmed: 24152688

55. Wang Q, Würtz P, Auro K, et al. Effects of hormonal contraception on systemic metabolism: cross-sectional and longitudinal evidence. Int Epidemiol. 2016; 45(5): 1445-1457, doi: 10.1093/ije/dyw147, indexed in Pubmed: 27538888.

56. Stumpf MA, Kluthcovsky AC, Okamoto JM, et al. Acute pancreatitis secondary to oral contraceptive-induced hypertriglyceridemia: a case report. Gynecol Endocrinol. 2018; 34(11): 930-932, doi: 10.1080/0951359 0.2018.1473365, indexed in Pubmed: 29782195.

57. Basaria S. Male hypogonadism. Lancet. 2014; 383(9924): 1250-1263, doi: 10.1016/S0140-6736(13)61126-5, indexed in Pubmed: 24119423.

58. Dimitriadis GK, Randeva HS, Aftab S, et al. Metabolic phenotype of male obesity-related secondary hypogonadism pre-replacement and post-replacement therapy with intra-muscular testosterone undecanoate therapy. Endocrine. 2018; 60(1): 175-184, doi: 10.1007/s12020-017-1516-x, indexed in Pubmed: 29396841.

59. Mohler ER, Ellenberg SS, Lewis CE, et al. The Effect of Testosterone on Cardiovascular Biomarkers in the Testosterone Trials. J Clin Endocrinol Metab. 2018; 103(2): 681-688, doi: 10.1210/jc.2017-02243, indexed in Pubmed: 29253154.

60. Zhang J, Yang B, Xiao W, et al. Effects of testosterone supplemen treatment in hypogonadal adult males with T2DM: a meta-analysis and systematic review. World J Urol. 2018; 36(8): 1315-1326, doi: 10.1007/s00345-018-2256-0, indexed in Pubmed: 29511802.

61. Rezanezhad B, Borgquist $\mathrm{R}$, Willenheimer R, et al. Association between serum levels of testosterone and biomarkers of subclinical atherosclerosis. Aging Male. 2018; 21(3): 182-186, doi: 10.1080/13685538.2017.1412 422, indexed in Pubmed: 29272977.

62. Zhang KS, Zhao MJ, An Q, et al. Effects of testosterone supplementation therapy on lipid metabolism in hypogonadal men with T2DM a meta-analysis of randomized controlled trials. Andrology. 2018; 6(1): 37-46, doi: 10.1111/andr.12425, indexed in Pubmed: 28950433.

63. Dos Santos Mota MP, Gomes Moura IC, Marinho RM, et al. Evaluation of Cardiovascular Risk in Climacteric Women: A Cross-Sectional Study. J
Midlife Health. 2018; 9(3): 123-129, doi: 10.4103/jmh.JMH 67 18, indexed in Pubmed: 30294183.

64. Welty F. Preventing clinically evident coronary heart disease in the postmenopausal woman. Menopause. 2004; 11(4): 484-494, doi: 10.1097/01. gme.0000111543.61545.86, indexed in Pubmed: 15243287.

65. Miller VM, Naftolin F, Asthana S, et al. The Kronos Early Estrogen Prevention Study (KEEPS): what have we learned? Menopause. 2019 [Epub ahead of print]; 26(9): 1071-1084, doi: 10.1097/GME.0000000000001326, indexed in Pubmed: 30939537.

66. Han D, Trooskin S, Wang X. Prevalence of cardiovascular risk factors in male and female patients with primary hyperparathyroidism. J Endocrinol Invest. 2012; 35(6): 548-552, doi: 10.3275/7861, indexed in Pubmed: 21750400.

67. Lacour B, Roullet JB, Liagre AM, et al. Serum lipoprotein disturbances in primary and secondary hyperparathyroidism and effects of parathyroidectomy. Am J Kidney Dis. 1986; 8(6): 422-429, doi: 10.1016/s0272-6386(86)80169-x, indexed in Pubmed: 3812471.

68. Godang K, Lundstam K, Mollerup $\mathrm{C}$, et al. The effect of surgery on fat mass, lipid and glucose metabolism in mild primary hyperparathyroidism. Endocr Connect. 2018; 7(8): 941-948, doi: 10.1530/EC-18-0259, indexed in Pubmed: 30300532

69. Murase T, Yamada N, Ohsawa N, et al. Decline of postheparin plasma lipoprotein lipase in acromegalic patients. Metabolism. 1980; 29(7): 666-672, doi: 10.1016/0026-0495(80)90112-2, indexed in Pubmed: 6991860

70. Werumeus Buning J, Dimova LG, Perton FG, et al. Downregulation of cholesteryl ester transfer protein by glucocorticoids: a randomised study on HDL. Eur J Clin Invest. 2017; 47(7): 494-503, doi: 10.1111/eci.12770 indexed in Pubmed: 28542805.

71. Dullaart RPF, De Vries R, Scheek L, et al. Type 2 diabetes mellitus is associated with differential effects on plasma cholesteryl ester transfer protein and phospholipid transfer protein activities and concentrations. Scand J Clin Lab Invest. 2004; 64(3): 205-215, doi: 10.1080/00365510410005721, indexed in Pubmed: 15222630

72. Duvillard L, Florentin E, Lizard G, et al. Cell surface expression of LDL receptor is decreased in type 2 diabetic patients and is normalized by insulin therapy. Diabetes Care. 2003; 26(5): 1540-1544, doi: 10.2337/diacare.26.5.1540, indexed in Pubmed: 12716819

73. Arnaldi G, Scandali VM, Trementino L, et al. Pathophysiology of dyslipidemia in Cushing's syndrome. Neuroendocrinology. 2010; 92(Suppl 1): 86-90, doi: 10.1159/000314213, indexed in Pubmed: 20829625.

74. Sinha RA, Singh BK, Yen PM. Direct effects of thyroid hormones on hepatic lipid metabolism. Nat Rev Endocrinol. 2018; 14(5): 259-269, doi: 10.1038/nrendo.2018.10, indexed in Pubmed: 29472712

75. Twickler TB, Cramer MJM, Dallinga-Thie GM, et al. Adult-onset growth hormone deficiency: Relation of postprandial dyslipidemia to premature atherosclerosis. J Clin Endocrinol Metab. 2003; 88(6): 2479-2488, doi: 10.1210/jc.2003-030278, indexed in Pubmed: 12788843.

76. Valdemarsson S, Hansson P, Hedner P, et al. Relations between thyroid function, hepatic and lipoprotein lipase activities, and plasma lipoprotein concentrations. Acta Endocrinol (Copenh). 1983; 104(1): 50-56, doi: 10.1530/acta.0.1040050, indexed in Pubmed: 6624364. 